\title{
Reshelving Study of Review Literature in the Physical Sciences
}

\section{Nancy J. Bułkovich}

Review publications contain articles that give overviews or state-of-the-art reports on specific topics. Although some review titles are published more frequently, many appear only once a year. At the Physical Sciences Library of the Pennsylvania State University's University Park Campus, a year-long reshelving study of the review publications collection was undertaken to determine usage of the titles. This need was fueled by a lack of shelf space, storage considerations, and the threat of serials cancellations. Three hundred review titles were examined. The best data were found in classes $Q C, Q D$, and QH-QP (monographic series only). The other classes had few titles or low use tallies. Approximately half of all titles were used at least once. Periodicals had a higher percentage of use than did monographic series.

cientific review publications provide a medium for substantive articles by giving overviews or state-of-the-art reports on specific topics. Many of these are annuals; others are review journals that are published more frequently. A study by Woodward and Hensman (1976) indicates that most of the top thirty scientific publications listed in Science Citation Index's "Journal Citation Reports," when ranked by impact factor, are review publications. An examination of the top thirty titles included in the 1992 "Journal Citation Reports-Journals Ranked by Impact Factor" (ISI 1993) indicates that the contents of over half the titles are primarily review articles.

In the Physical Sciences Library of Pennsylvania State University's University
Park campus, these titles had been segregated in a separate, noncirculating reference collection. At the time of this study the physical sciences branch library had approximately 88,000 volumes and 850 current serial subscriptions. There were eight separate reference collections, including the one in this study, as well as separate monograph and journal collections. The major subject areas were astronomy, physics, and chemistry. Secondary subject areas included biochemistry, pharmaceutical chemistry, chemical engineering, and medicinal chemistry.

A number of factors provided the impetus for this survey. First, the collection was about to fill the designated shelf space, and no additional space was available. The most obvious solution to this

NanCY J. Butкovich is Librarian at the Physical Sciences Library at Pennsylvania State University, University Park, Pennsylvania (e-mail: njb@psulias.psu.edu). The author wishes to thank Sue Houser for her assistance with the marking and reshelving of these publications during the course of this project. The author also wishes to thank Bonnie MacEwan and Linda Musser for their comments. Manuscript received August 11, 1995; accepted for publication November 16,1995 . 
space problem was to incorporate these publications into other parts of the collection. Such a shift would also simplify access to the collection by reducing the number of reference collections a person would have to check in order to find a desired title.

The monograph and the journals collections were also reaching their total capacities, so plans were being made for moving a portion of the collections to remote storage facilities. Use data, particularly concerning the age of the material used, could help justify moving certain titles either in part or in total to a remote storage facility, a situation similar to that described by Naylor $(1993,28)$ and Rice $(1979,35,36)$.

Because the collection was noncirculating, no use data was available for it, and once the collection was merged into the journal and monograph collections, the titles would become anonymous. Therefore, another use for the data involved the need to have a list of low-use titles available in the event that a serials cancellation project was necessary. This possible use for the data is not unique to this study. Naylor (1993, 28) and Swigger and Wilkes $(1991,41,42)$ reported similar reasons for conducting use studies of serial titles. Bustion and Treadwell used reshelving data to evaluate the reliability of faculty use surveys that had been used as the basis for a serials cancellation project (1990, 142-43).

The data from this project would be combined with results from faculty surveys, SciSearch rankings of publications cited by Penn State faculty, and other sources of information to identify titles for future serial cuts. Although each method has weaknesses that are well documented in the literature (Rice 1979, 36-37; Swigger and Wilkes 1991, 42-44), the combination of the data from these different methods would provide a useful measure of the use of these titles.

Reshelving statistics are often used as a measure of collection use (Rice 1979; Swigger and Wilkes 1991; Naylor 1990, 1993, and 1994). The method chosen for this study is similar to the "sweep" method described by Naylor, who found that this method produced higher use values than did a second method that required patrons to mark their usage on labels attached to the journal covers $(1993,30,62$; 1994, 373-74, 378).

\section{METHODOLOGY}

Data were collected in the following manner:

- A book cart was placed next to the Reference Review collection and was labeled with a sign asking patrons not to reshelve review titles.

- One staff member was given the responsibility of marking and reshelving these titles. Other staff and student employees were instructed not to reshelve this material unless they had instructions for marking the material. Instead, they were to leave items on the cart for the staff member assigned to the project to mark and reshelve.

- Each item was marked on the inside front cover prior to being reshelved. This location was chosen over marking the spine or outside cover in order to reduce the chance of data being lost.

- The project was conducted for a period of one year, from October 1991 to October 1992. All titles in the collection were included, regardless of whether or not they were new or current subscriptions or ceased or canceled titles.

- At the end of the project, the data were tabulated.

Although Ross reported success in an unobtrusive study of patron browsing behavior (1983, 269-76), no effort was made to account for materials reshelved by patrons. As Naylor noted, "One assumes that this type of behavior is proportional for all journals" $(1990,9)$. Given the staffing limitations and the fact that faculty have keys that give them twenty-four-hour access to the Physical Sciences Library, any attempt to obtain this information would be impractical and prohibitively costly.

\section{RESULTS}

A total of 300 titles was included in this project. These titles were broken down 
into periodicals and series. According to the ALA Glossary of Library and Information Science (Young 1983, 166), "periodical" is defined as:

A serial appearing or intended to appear at regular or stated intervals, generally more frequently than annually, each issue of which is numbered or dated consecutively and normally contains separate articles, stories, or other writings.

The same source (Young 1983, 204) defines "series" as:

A group of separate bibliographic items related to one another by the fact that each item bears, in addition to its own title proper, a collective title applying to the group as a whole.

Of the 300 titles, 250 were series, most of which were either monographic series or annual reviews, and 50 were periodicals. A few titles were sets with one publication date. These were included with the monographic series. Approximately $50 \%$ (151 titles) were used at least once during the study period. Of the 250 monographic series, 110 (44\%) were used, and of the 50 periodicals, $41(82 \%)$ were used (see table 1 for a more detailed breakdown of usage, sorted by Library of Congress classification).

The greatest usage of the collection based on the number of titles held was in the QC and QD ranges (physics and chemistry). However, over $50 \%$ of titles in the QBs (astronomy) and TA-TP (engi- neering and technology) were used during the survey period.

An examination of the individual uses of each title (see table 2) also shows a high rate of use in the QH-QP area (life sciences) in addition to the QCs and QDs. High average use per title was found among monographic series in the QBs (astronomy) and review periodicals in the TA-TP (engineering).

These data become even more impressive when the number of titles used instead of the number of titles held are compared with the number of uses. For instance, the QBs would have an average of 11 uses per title, instead of the average of 7 uses per title if all titles held were counted. Titles that are broadly categorized as medicine (RA-RS) showed relatively light use. The one forensic science title (HV) is omitted from this table, because it was not used during the study period.

Because the possibility exists of using these data for remote storage considerations, knowing the age of the materials being used becomes important. The usage of monographic series and review periodicals sorted by LC classification and by date of publication appear in tables 3 and 4. When more than one year was included in a physical volume, the date used was the oldest included in that volume. LC classes that had fewer than 50 uses per document type were not included, since the data sets were too small to give meaningful results.

TABLE 1

Number of Titles aNd Number of Titres USEd (ARRANGED BY LC Class)

\begin{tabular}{lccccc}
\hline & & \multicolumn{3}{c}{ Totals } \\
& & \multicolumn{2}{c}{ Monographic Series } & \multicolumn{2}{c}{ Review Periodicals } \\
LC Class & No. Titles & No. Titles & No. Used & No. Titles & No. Used \\
\hline HV & 1 & 1 & 0 & 0 & 0 \\
QB & 5 & 3 & 2 & 2 & 1 \\
QC & 51 & 39 & 16 & 12 & 11 \\
QD & 183 & 154 & 71 & 29 & 23 \\
QH-QP & 24 & 24 & 9 & 0 & 0 \\
RA-RS & 14 & 11 & 4 & 3 & 2 \\
TA-TP & 22 & 18 & 8 & 4 & 4 \\
\hline
\end{tabular}


TABLE 2

Total Number of Titles Held and Individual Uses of Those Titles (ARRANGED BY LC Class)

\begin{tabular}{lcccc}
\hline & \multicolumn{2}{c}{ Monographic Series } & \multicolumn{2}{c}{ Review Periodicals } \\
LC Class & No. Titles Held & No. Uses & No. Titles Held & No. Uses \\
\hline QB & 3 & 22 & 2 & 1 \\
QC & 39 & 70 & 12 & 65 \\
QD & 154 & 497 & 29 & 419 \\
QH-QP & 24 & 195 & 0 & 0 \\
RA-RS & 11 & 12 & 3 & 3 \\
TA-TP & 18 & 30 & 4 & 23 \\
\hline
\end{tabular}

TABLE 3

USAGE OF MONOGRAPHIC SERIES

(SORTED by LC Classification ANd by Date of PUblication)

\begin{tabular}{|c|c|c|c|c|c|c|}
\hline \multirow{3}{*}{$\frac{\text { Date }}{1988-1992}$} & \multicolumn{6}{|c|}{ LC Classification } \\
\hline & \multicolumn{2}{|c|}{ QC } & \multicolumn{2}{|c|}{$\mathrm{QD}$} & \multicolumn{2}{|c|}{$\mathrm{QH}-\mathrm{QP}$} \\
\hline & 34.3 & (24) & 26.6 & (132) & 28.7 & (56) \\
\hline $1983-1987$ & 8.6 & (6) & 21.7 & $(108)$ & 30.8 & (60) \\
\hline 1978-1982 & 25.7 & (18) & 17.7 & (88) & 25.6 & (50) \\
\hline $1973-1977$ & 11.4 & (8) & 13.1 & (65) & 6.7 & (13) \\
\hline $1968-1972$ & 8.6 & (6) & 9.1 & (45) & 5.6 & (11) \\
\hline $1963-1967$ & 8.6 & (6) & 6.6 & $(33)$ & 2.1 & (4) \\
\hline $1958-1962$ & 1.4 & (1) & 28 & (14) & 0.0 & \\
\hline $1953-1957$ & 1.4 & (1) & 1.8 & (9) & 0.5 & (1) \\
\hline $1948-1952$ & 0.0 & & 0.4 & $(2)$ & 0.0 & \\
\hline $1943-1947$ & 0.0 & & 0.0 & & 0.0 & \\
\hline $1938-1942$ & 0.0 & & 0.2 & (1) & 0.0 & \\
\hline
\end{tabular}

'The total number ( $\mathrm{n}$ ) of uses is listed in parentheses. All columns total $100 \%$

Limitations of THE Methodology

Although surveys like this are enticing because of their simplicity, they do have weaknesses that limit the usefulness of the data obtained. Some of the major problems are listed below.

- The way in which the item was used is unknown (Rice 1979, 36; Swigger and Wilkes 1991, 42).
- The patron may have reshelved the material rather than leaving it for the library staff to reshelve (Rice 1979, 36; Swigger and Wilkes 1991, 42; Naylor 1993, 28).

- A library employee who is not involved in the project could reshelve materials without marking them.

In spite of these weaknesses the data obtained from this sort of project can be 
TABLE 4

Percentage of Review Periodicals

(SORTEd by LC Classification and by Date of Publication)

\begin{tabular}{|c|c|c|c|c|}
\hline \multicolumn{5}{|c|}{ LC Classification } \\
\hline \multirow{2}{*}{$\frac{\text { Date }}{1988-1992}$} & \multicolumn{2}{|c|}{$Q C$} & \multicolumn{2}{|c|}{ QD } \\
\hline & 58.5 & (38) & 40.8 & (171) \\
\hline 1983-1987 & 21.5 & (14) & 19.8 & (83) \\
\hline 1978-1982 & 9.2 & (6) & 12.9 & (54) \\
\hline 1973-1977 & 1.5 & (1) & 8.6 & (36) \\
\hline 1968-1972 & 4.6 & (3) & 9.3 & (39) \\
\hline 1963-1967 & 1.5 & (1) & 2.9 & (12) \\
\hline 1958-1962 & 0.0 & & 1.9 & (8) \\
\hline $1953-1957$ & 1.5 & (1) & 1.2 & (5) \\
\hline $1948-1952$ & 1.5 & (1) & 2.2 & (9) \\
\hline 1943-1947 & - & & 0.0 & \\
\hline 1938-1942 & - & & 0.2 & (1) \\
\hline 1933-1937 & - & & 0.0 & \\
\hline 1928-1932 & - & & 0.2 & (1) \\
\hline
\end{tabular}

"The number of uses ( $\mathrm{n}$ ) is given in parentheses. The QD percent column totals $100 \%$; the QC column totals $99.8 \%$ due to round-off error.

useful, particularly when used in conjunction with data from other sources. However, one should keep in mind that the values obtained are minimums and not absolutes and that the results from classification areas represented by few titles are going to be poor.

\section{Conclusions}

The best data were found in classes QC, $\mathrm{QD}$, and QH-QP (monographic series only). The other classes had few titles or low use tallies, and so the data were less reliable. It should also be noted that these data represent large user populations in this particular library, and a library serving a different mix of clientele would show different patterns of use.

With these sources of error in mind, the data can be summarized as follows:

- Approximately half of all titles were used at least once.

- Periodicals had a higher percentage of use than did monographic series, possibly because there were more issues.
- Approximately $80 \%$ of the physics monographic series and $79 \%$ of the chemistry series volumes used were published since 1973. The area broadly categorized as life sciences reached $85 \%$ by 1978 .

- For periodicals, physics titles reached the $80 \%$ mark by 1983 , and chemistry reached $82 \%$ of its usage in items published since 1973.

Partly as a result of this project, periodical titles were incorporated into the journal collection, while series were merged into the monograph collection. These series can now circulate. Keeping in mind the limitations of the data, these results will be used in conjunction with data from other sources to identify potential items for cancellation lists or for transfer to remote storage facilities.

\section{WORKS CITED}

Bustion, Marifran, and Jane Treadwell. 1990. Reported relative value of journals versus use: A comparison. College o research libraries 51: 142-51. 
Institute for Scientific Information (ISI) 1993. Science Citation Index journal citation reports. Philadelphia: ISI.

Naylor, Maiken. 1990. Accessing current periodical use at a science and engineering library: A dBASE III+ application. Serials review 16: 7-19.

__ 1993. A comparison of two methodologies for counting current periodical use, Serials review 19: 27-34, 62 .

- 1994 . Comparative results of two current periodical use studies. Library resources d technical services 38: 373-88.

Rice, Barbara A. 1979. Science periodicals use study. Serials librarian 4: 35-47.

Ross, Johanna. 1983. Observations of browsing behavior in an academic library. College \& research libraries 44; 269-76.

Swigger, Keith, and Adeline Wilkes. 1991. The use of citation data to evaluate serials subscriptions in an academic library. Serials review 17: 41-46, 52 .

Woodward, A. M., and Sandy Hensman. 1976. Citations to review serials. Journal of documentation 32: 290-93.

Young, Heartsill, ed 1983. ALA glossary of library and information science. Chicago: American Library Association.

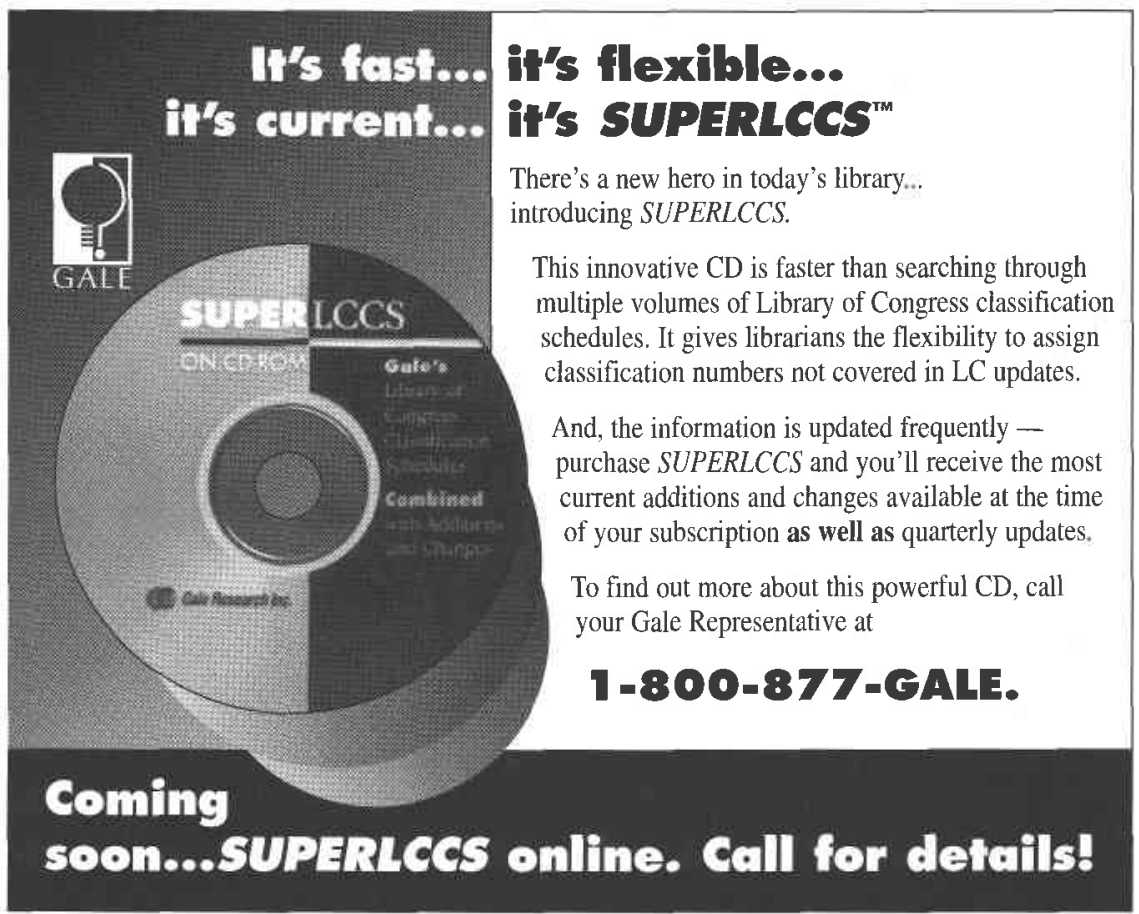

